\title{
Dependence of cyanobacteria defense mode on grazer pressure
}

\author{
Edyta Fiałkowska*, Agnieszka Pajdak-Stós \\ Department of Hydrobiology, Institute of Environmental Sciences, Jagiellonian University, \\ Gronostajowa 3, 30-387 Kraków, Poland
}

\begin{abstract}
In a series of experiments we investigated the ability of a cyanobacterium of the genus Phormidium to defend itself against the ciliate grazer Furgasonia blochmanni. The experiments showed that the cyanobacterium can employ different modes of defense, depending on grazer density. Under high grazer pressure, each mat of Phormidium instantly formed a dense clump surrounded by a mucilage layer. Trichomes remaining inside such clumps were completely inaccessible to ciliates. Under medium pressure, the defense reaction was slower and consisted in enhanced sheath production by individual trichomes. The effectiveness of such a defense was also very high, as clearly reflected in the condition of the ciliates. When the pressure was low, the cyanobacteria did not exhibit any form of defense, dispersing evenly all over the bottom in a pattern similar to that observed in control mats. We conclude that the cyanobacterium is able to modify its defense reaction according to the real grazing risk.
\end{abstract}

KEY WORDS: Cyanobacteria $\cdot$ Anti-herbivore defense $\cdot$ Ciliate pressure

\section{INTRODUCTION}

As predation is one of the main direct causes of external mortality, living organisms have been increasing their chances of survival by evolving various defense mechanisms. The most common are known as constitutive defenses - constant features of organisms present independently of predation risk. In contrast, inducible defenses require environmental stimuli to be activated (Harvell 1990). It was earlier suggested that the main advantage of inducible defense is the fact that its cost is borne only when necessary; that is, when there is a real danger of predation (Harvell 1990). More recent studies, however, imply that some defenses might not incur any cost or that inducibility per se can be an advantage, helping to prevent coevolution of attackers (Tollrian \& Harvell 1999).

Inducible defenses in aquatic systems have attracted much attention in recent decades. Predator-induced

*E-mail: efialk@eko.uj.edu.pl morphological changes have been described in fish (Broenmark \& Miner 1992), amphibians (Smith \& Van Buskirk 1995) and aquatic invertebrates including cladocerans, rotifers, bryozoans (reviewed by Havel 1987, Dodson 1989, Harvell 1990) and ciliates (Kuhlmann \& Heckmann 1985, Washburn et al. 1988, Fyda 1998). It was shown that the prey's response can be modified depending on predator density (Fyda \& Wiąckowski 1998, Wiąckowski \& Starońska 1999).

Anti-herbivore defense in aquatic systems has also been studied. Some algae can defend themselves against grazers by deterring them with chemicals (Van Alstyne 1988, Wolfe et al. 1997), whereas others avoid grazing owing to morphological plasticity (Lewis et al. 1987, Luerling \& Van Donk 1997). Such plasticity in the algal genus Scenedesmus ensures its resistance to grazing by many different types of herbivores (Luerling 1999).

Inducible defense against ciliate grazers was also described in such simple organisms as cyanobacteria (Fiałkowska \& Pajdak-Stós 1997, Pajdak-Stós et al. 2001). Two strains of Phormidium, referred to as Ph1 
and $\mathrm{Ph} 2$, revealed an inducible defense capability against ciliates by means of withdrawing inside the sheaths when disturbed by grazers. Trichomes ending in empty sheaths turned out to be completely inaccessible for the ciliates (Fiałkowska \& Pajdak-Stós 1997). In Phormidium autumnale, the same purpose is served by a protective layer of extracellular polysaccharides (EPS) shielding the initial piece of mat in which filaments are embedded; the defense reaction is engaged in the presence of different grazer species (Pajdak-Stós et al. 2001). However, the phenomenon was investigated only at invariable grazer density. During closer observations of the cyanobacteria mats used for feeding our ciliate cultures, we noticed interesting changes in their appearance. We suspected that those changes might be related to different ciliate densities in the culture dishes and designed a set of experiments to determine whether the cyanobacteria mode of defense depends on grazer pressure.

\section{MATERIALS AND METHODS}

A strain of an unidentified species of the cyanobacterium Phormidium called $\mathrm{Ph} 2$ in our previous paper (Fiałkowska \& Pajdak-Stós 1997) and a clone of a nassulinid ciliate Furgassonia blochmanni were used for experiments. This free-living, freshwater ciliate occurs naturally in ponds and puddles along with filamentous cyanobacteria like Ph2, which form mats on the sediment surface. F. blochmanni is equipped with a cytopharyngeal apparatus, a highly specialized structure that enables the ciliate to ingest long threads of cyanobacteria (Eisler \& Bardele 1986, Vigues et al. 1999).

Clonal populations of experimental organisms were obtained from a single filament (Phormidium sp.) and a single cell (Furgassonia blochmanni) taken from an aquarium maintained non-axenically at the Department of Hydrobiology, Jagiellonian University, Kraków. The cyanobacterium was cultured in Petri dishes, in BG11 medium (Stanier et al. 1971), prepared according to a formula obtained from the Culture Collection of Algae and Protozoa (Ambleside, UK), where it formed thin mats on the bottom. The clone of $F$. blochmanni was cultured in Żywiec brand mineral water and fed the strain of Phormidium later used for the experiments. The ciliate was identified after Protargol staining (Tuffrau 1967) as modified by Wilbert (1975). All cultures were kept at a light intensity of $70 \mu$ mol photon $\mathrm{m}^{-2} \mathrm{~s}^{-2}$ under a $12 \mathrm{~h}$ light:12 h dark cycle at temperatures ranging from $26^{\circ} \mathrm{C}$ in light periods to $21^{\circ} \mathrm{C}$ in darkness.

Prior to the experiments the ciliates were starved for $24 \mathrm{~h}$. Then 36 approximately equal-sized $(1 \times 1 \mathrm{~mm})$ pieces cut from the Phormidium mat formed in culture were each placed in a well of 24-Well PS TC Testplate (Renner $\mathrm{GmbH}$ ). The wells were divided into four 9 -well groups. One of them served as the control. Ciliates were transferred individually with a pipette to each well of the other groups: 10 to each well in the second group, 100 in the third and approximately 600 in the fourth. To obtain the density of 600 ciliates $\mathrm{ml}^{-1}$, we first concentrated them on a culture dish by gently swirling it and shedding the excess medium, then transferred them to a small Erlenmeyer flask. Ciliate density in the flask was estimated by counting their number in a few $1 \mathrm{ml}$ samples and adjusting it to the desired magnitude by adding small amounts of BG11 medium. BG11 medium was added to the remaining wells so that each well contained approximately $1 \mathrm{ml}$ medium.

The wells were subsequently examined under an OLYMPUS SZ-11 binocular microscope at a total magnification of $18 \times$. To show the cyanobacteria reaction to grazer pressure, the mats were recorded on VHS tape half an hour and then again $2 \mathrm{~h}$ after ciliate release (Fig. 1). Further observations made with an OLYMPUS IMT-2 inverted microscope with Nomarski contrast, working at a total magnification of $150 \times$, revealed that, depending on the grazer pressure, there were noticeable differences in the velocity and direction of trichome movements. To analyse them we additionally recorded randomly chosen fragments of mats in 3 wells of each treatment $1 \mathrm{~h}$ after grazer release. We checked the velocity of 10 trichomes from each recorded mat fragment for low and medium grazer density, and also the control. As the movements of trichomes under the strongest pressure were unlike those in other treatments, to visualize them we superimposed 4 video frames taken at $4 \mathrm{~s}$ intervals, which produced a stroboscopic-like image (Fig. 2).

All the recordings were made with a SONY CCDIRIS camera. The measurements were made from the recorded material with the help of the MultiScan image analysis program (Computer Scanning System), which was also used for digital processing of the photographs presented in this paper.

We used ciliate condition as a simple indirect measure of cyanobacteria defense effectiveness. All ciliates released into the experimental wells at the start of the experiment were starved. Two hours after releasing the grazers, 50 randomly chosen individuals from wells with densities of 600 and 100 ciliates $\mathrm{ml}^{-1}$, and all individuals from wells with 10 ciliates $\mathrm{ml}^{-1}$ were categorized under $150 \times$ magnification as cysts, starved and satiated. Then the fractions of those categories were calculated. The procedure was repeated after 24 and $72 \mathrm{~h}$ in 3 different wells each time to assure the independence of the data. All totally transparent individu- 
als, without any visible trace of food inside the vacuoles, were categorized as starved, whereas all individuals with visible greenish food vacuoles were categorized as satiated. The proportion of cysts out of all counted ciliates and the proportion of satiated individuals out of all non-encysted ones were used as measures of grazer condition for calculations.
The trichomes with empty sheaths among 50 randomly chosen filament endings along the edge of the mat were counted 2, 24 and $72 \mathrm{~h}$ after the beginning of the experiment in 3 different wells each time. When fewer than 50 filaments were sticking out of the mat, as occurred especially in the wells with 600 and 100 ciliates $\mathrm{ml}^{-1}$, we counted all the filament endings available.
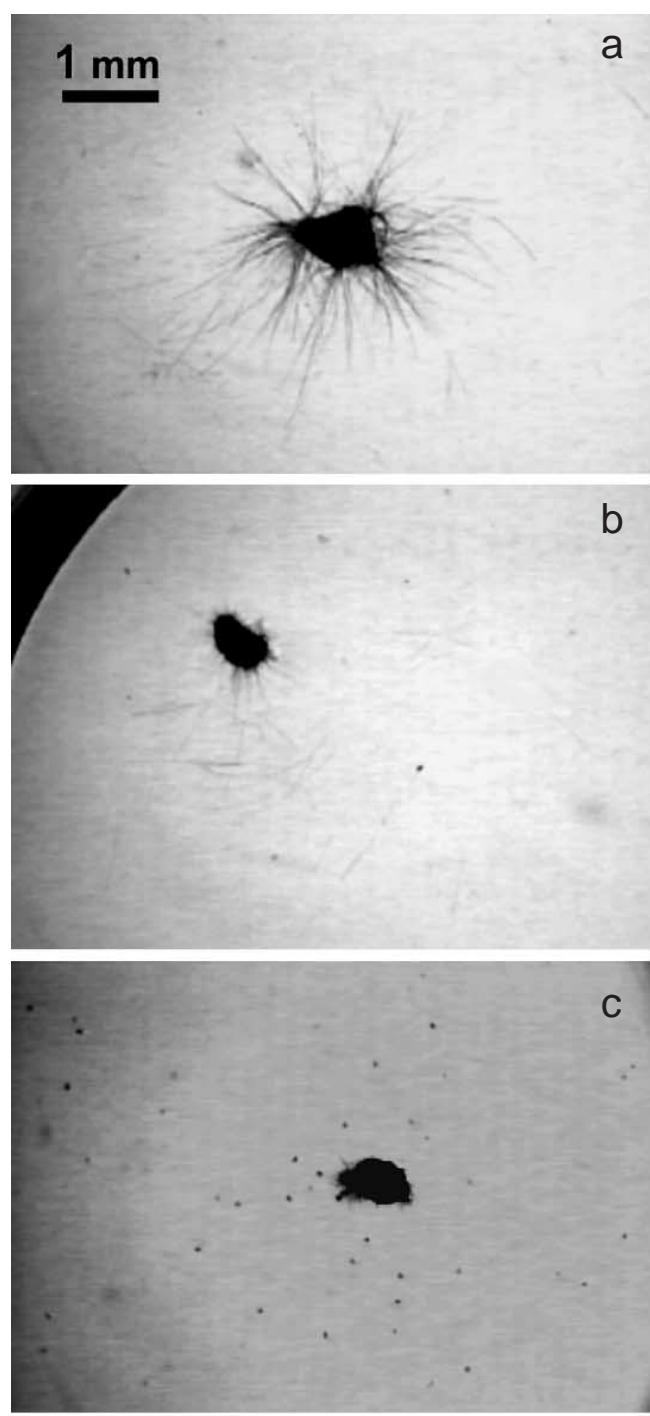

Fig. 1. Appearance of cyanobacteria Phormidium sp. mats (a) in control wells and subjected to grazing pressures of Furgasonia blochmanni at densities of (b) 10 ciliates $\mathrm{ml}^{-1}$, (c) 100 ciliates $\mathrm{ml}^{-1}$ and (d) 600 ciliates $\mathrm{ml}^{-1}$. The left column shows the mats half an hour and the right column $2 \mathrm{~h}$ after ciliate release

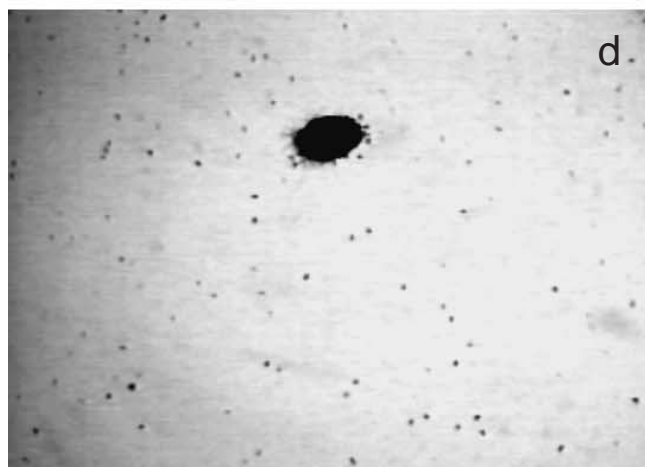

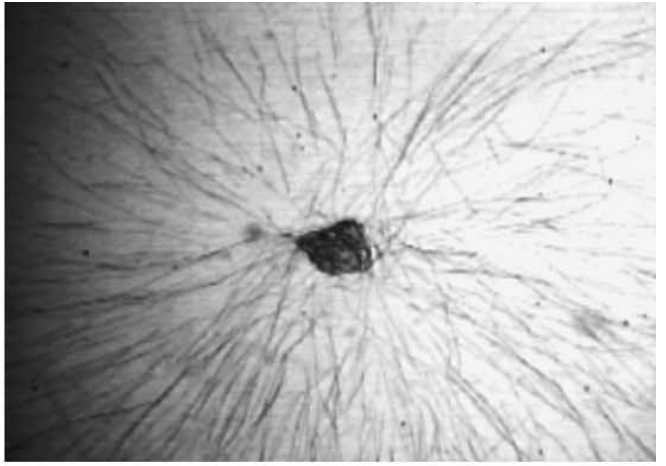
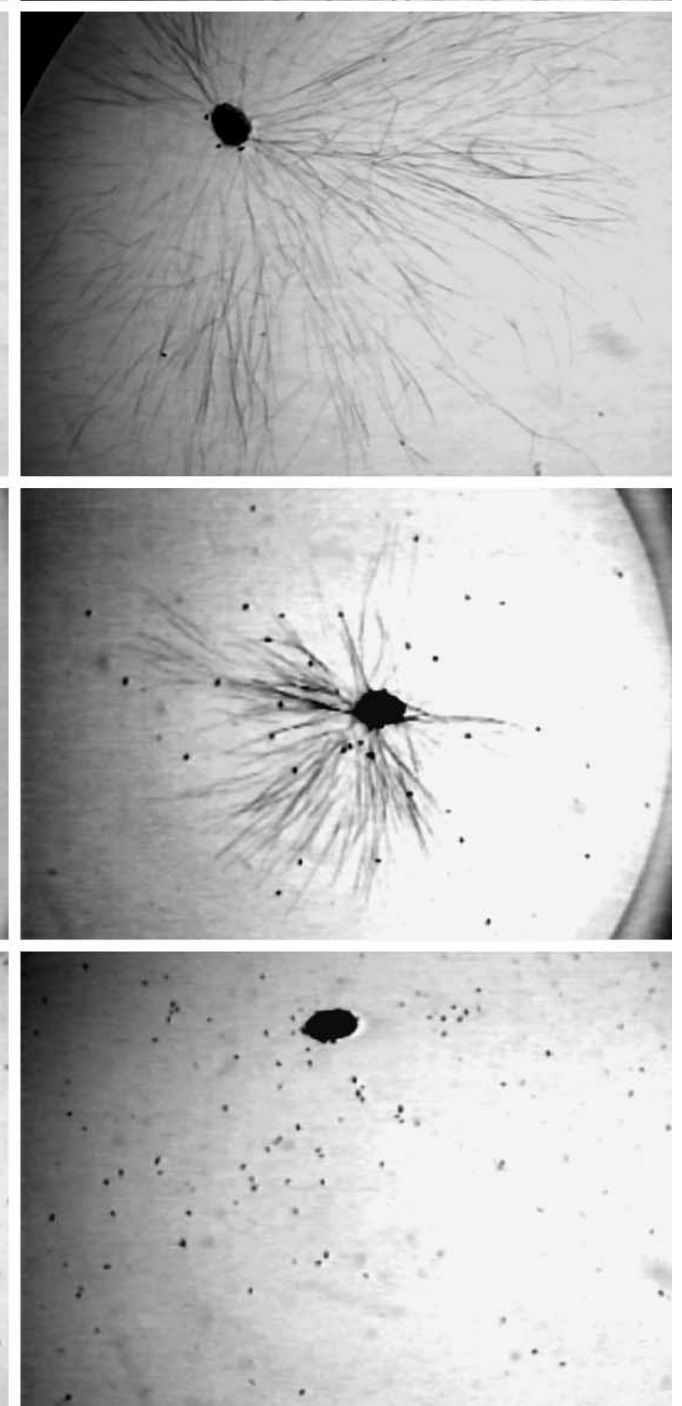


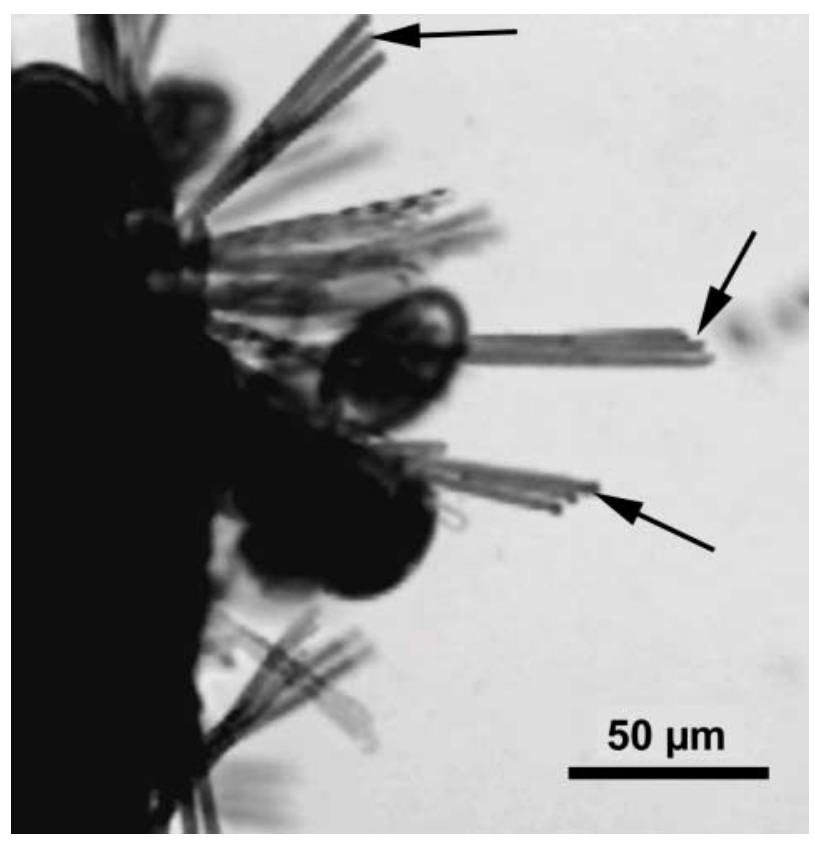

Fig. 2. Stroboscopic-like image of rotating movements of short trichome endings at the edge of a Phormidium sp. mat subjected to a pressure of Furgasonia blochmanni at a density of 600 ciliates $\mathrm{ml}^{-1}$. Each arrow indicates a single trichome recorded at four $4 \mathrm{~s}$ intervals $1 \mathrm{~h}$ after ciliate release

Analysis of variance (2-way ANOVA) on $\arcsin \sqrt{ } \mathrm{p}$ (where $\mathrm{p}$ is proportion) transformed data (Sokal \& Rohlf 1981) was used to check whether the mean percentage of satiated ciliates and cysts, as well as the mean percentage of trichomes ending in empty sheaths, changed significantly over time dependent on grazer density.

\section{RESULTS}

Fig. 1 shows the difference in the appearance of cyanobacterium mats subjected to different grazer pressures half an hour and $2 \mathrm{~h}$ after ciliate release. In the control wells, without grazing, trichomes started to move from the initial piece of mat, leaving the original mucilage layer, immediately after being transferred. Two hours later they were dispersed over the whole bottom. That brought about a conspicuous decrease in the density of trichomes within the initial mat (Fig. 1a). When grazer density was very low $\left(10\right.$ ciliates $\left.\mathrm{ml}^{-1}\right)$, trichome dispersion began quickly, and after $2 \mathrm{~h}$ they covered the bottom in a pattern similar to that in the control (Fig. 1b). Under medium grazer pressure (100 ciliates $\mathrm{ml}^{-1}$ ), trichome dispersion was more limited than in the control and low-ciliate-density wells, although during the $2 \mathrm{~h}$ in which the trichomes moved from the initial mat, their ability to disperse was apparently limited (Fig. 1c). At a density of 600 ciliates $\mathrm{ml}^{-1}$, the trichomes did not disperse at all. Apart from very short endings sticking out from the initial mat, mainly at the beginning of the experiment, there were no trichomes on the well bottom (Fig. 1d). Each mat subjected to high grazer pressure turned into a dense clump with trichomes embedded in a layer of mucilage enclosing the whole initial mat (Fig. 3).

Cyanobacteria trichomes on the bottom moved to and fro along their longitudinal axes approximately $1 \mathrm{~h}$ after ciliate release under weak and moderate grazing pressure (10 and 100 ciliates $\left.\mathrm{ml}^{-1}\right)$, and also in the control. The velocity of trichomes varied between 0.5 and $2.1 \mathrm{\mu m} \mathrm{s}^{-1}$, in wells with 10 and 100 ciliates ml ${ }^{-1}$ as well as in the control. In mats subjected to the highest ciliate density $\left(600\right.$ ciliates $\left.\mathrm{ml}^{-1}\right)$, trichomes sticking out of the piece of mat rotated without any contact with the bottom. As we were unable to measure motility rate, we showed the movement on a stroboscope image of trichome position at four $4 \mathrm{~s}$ intervals (Fig. 2).

The fraction of satiated ciliates changed significantly with the time of cyanobacteria exposure to grazing pressure (ANOVA, $F_{4,18}=14.68, \mathrm{p}<0.01$ ). Under the highest grazer density, the fraction of satiated ciliates decreased significantly during the first $24 \mathrm{~h}$ of the experiment (Tukey's HSD test, $\mathrm{p}<0.01$ ), and further decrease was not significant ( $p>0.1$ ) (Fig. 4). At a medium ciliate density, the fraction of satiated ciliates dropped significantly only between the first and third days $(p<0.01)$. The pattern was different in the wells

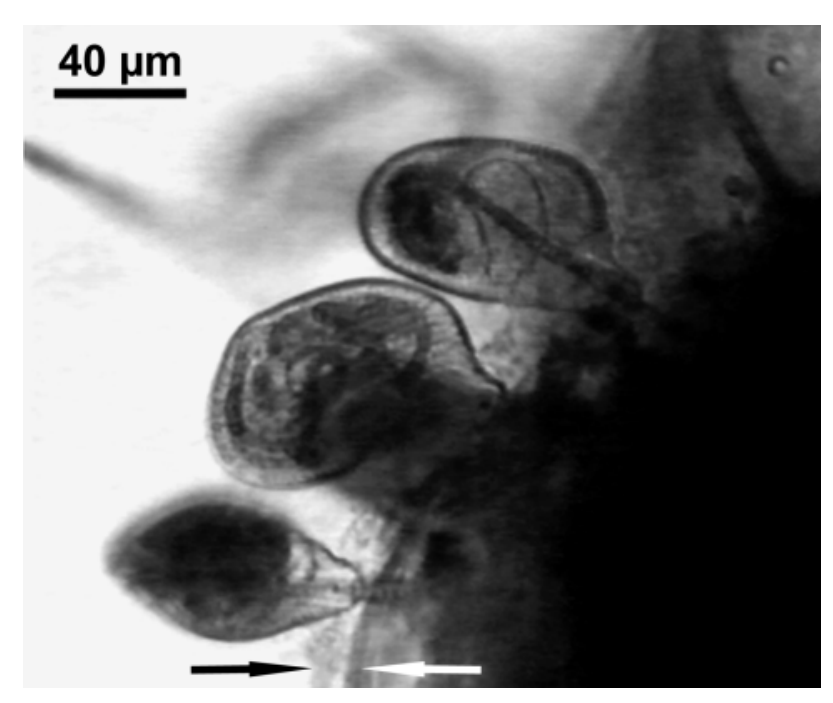

Fig. 3. Appearance of a cyanobacteria Phormidium sp. clump $2 \mathrm{~h}$ after ciliate release. Furgasonia blochmanni ingest trichomes protruding from the clump. Black arrow indicates the mucilage layer embedding the clump; white arrow indicates trichomes arranged parallel to its edge 
with the lowest ciliate density; the fraction of satiated ciliates remained at the same high level throughout the experiment (Fig. 4).

ANOVA showed that the fraction of cysts changed significantly during the experiment $\left(F_{4,18}=48.18, \mathrm{p}<\right.$ 0.01 ) between the first and the third days (Tukey's HSD test, $\mathrm{p}<0.01$ ) only under a grazer density of 600 ciliates $\mathrm{ml}^{-1}$. In the remaining treatments there were no differences in the fraction of cysts between time intervals (Fig. 5).

Fig. 6 shows how the percentage of trichomes ending in empty sheaths changed throughout the experiment in all treatments. We did not include the highest density treatment $\left(600\right.$ ciliates $\left.\mathrm{ml}^{-1}\right)$ in the statistical tests, as after $2 \mathrm{~h}$ of the experiment there were only a few trichomes sticking out of the EPS layer surrounding the initial piece of mat, and none of them ended with an empty sheath. The effect of the interaction between time and treatment was significant (ANOVA, $\left.F_{4,18}=10.08, \mathrm{p}<0.01\right)$. There was a significant difference in the percentages of trichomes ending in empty sheaths in the medium grazer pressure treatment between the first and third days (Tukey's HSD test, $\mathrm{p}<$ 0.01 , whereas in the remaining treatments the difference between days was not significant.

\section{DISCUSSION}

In our previous papers (Fiałkowska \& Pajdak-Stós 1997, Pajdak-Stós et al. 2001) we showed that cyanobacteria are able to survive grazer pressure as a result of different defense modes. The results presented in this paper indicate an ability to modify the means of defense according to initial grazer pressure. As shown in Fig. 1, trichomes in the control wells dispersed

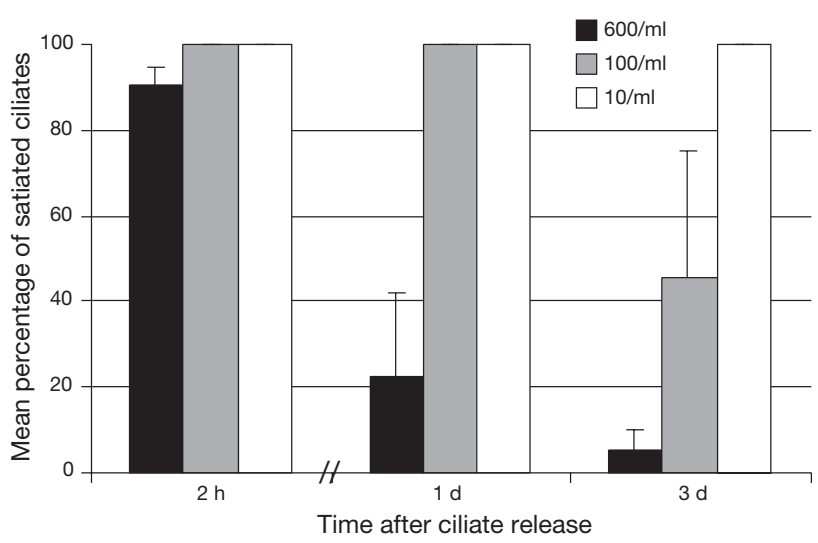

Fig. 4. Effectiveness of cyanobacteria Phormidium sp. defense as measured by the mean percentage of satiated ciliates Furgasonia blochmanni calculated for 3 replicates. Error bars indicate standard deviations

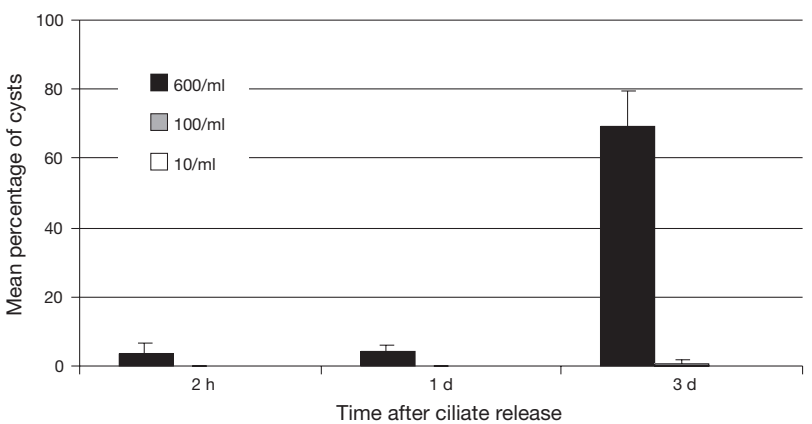

Fig. 5. Furgasonia blochmanni. Mean percentage of cysts calculated as means of 3 replicates. Error bars indicate standard deviations

evenly all over the bottom, whereas the dispersion of those subjected to ciliate grazing was apparently limited. What is more, the trichomes' ability to disperse seemed to change proportionally to grazer density. When ciliate density was low, the trichomes moved farther away from the mat, and their density around it was lower than that under medium grazer pressure (Fig. 1b,c). The velocity of the trichomes, which did not vary much between the control and the treatments, cannot account for these differences. In different strains of Phormidium, trichomes react to ciliate attacks by gliding away from the grazer's location (Fiałkowska \& Pajdak-Stós 1997). This could explain the limited extent of trichome dispersion. Under stronger grazer pressure, when the probability of attack is relatively high, trichomes are forced to change movement direction repeatedly, and consequently their ability to colonize the bottom is lower. The defense reaction was even more pronounced when grazer pressure was 600 ciliates $\mathrm{ml}^{-1}$ (Fig. 1d). The frequency of ciliate attacks at the beginning of the experiment must have been so high that it was impossible for trichomes to leave the initial piece of mat. Instead the cyanobacteria

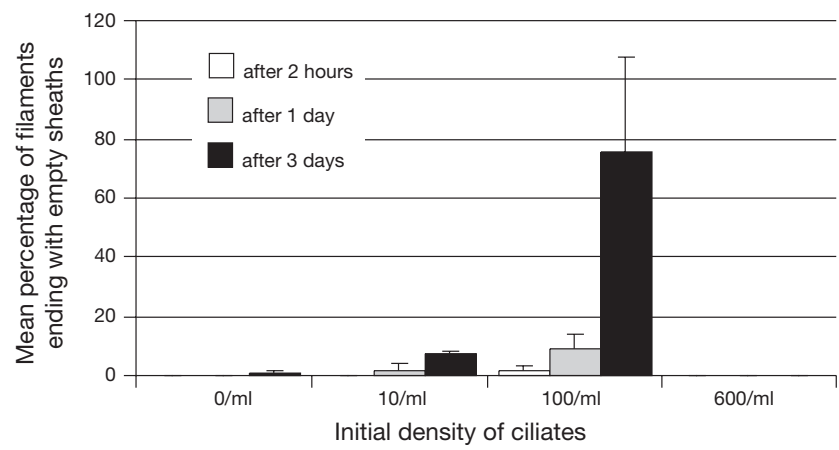

Fig. 6. Phormidium sp. Mean percentage of trichomes ending with empty sheaths in each experimental treatment for 3 replicates. Error bars indicate standard deviations 
formed dense clumps embedded in mucilage with very short pieces of trichomes sticking out. Their movements were completely different from those in all the remaining treatments. Here the trichomes at the edge of the clumps rotated almost without any change of their distance in relation to the mat (Fig. 2). As cyanobacteria have been reported to react to mechanical stimuli (Haeder \& Hoiczyk 1992), it seems likely that in the described case many ciliates swimming constantly around the mat in search of food touched the trichomes repeatedly, making them move. Still, the trichomes did not leave the initial piece of mat. Most surprising is the final effect of such behavior. Only $24 \mathrm{~h}$ after grazer release, the mats formed dense clumps surrounded by a thin layer of mucilage, with almost no trichomes sticking out. They remained this way until the end of the experiment (Fig. 7d).

The mucilage has been reported to play an important role in the protection of Phormidium autumnale against ciliate grazers (Pajdak-Stós et al. 2001). Even though it could not be unequivocally stated that the mucilage is accumulated in the presence of grazers, it was shown that a layer of mucilage ensures survival of cyanobacteria trichomes remaining inside it by making them completely inaccessible for grazers (Pajdak-Stós et al. 2001). A similar situation seems to take place in the case of $\mathrm{Ph} 2$ mats subjected to the highest experimental grazer pressure. Two hours after ciliate release, the mats in the form of dense clumps were already embedded in a mucilage layer (Fig. 3). Due to difficulties in obtaining data concerning mucilage mass when working with such small amounts of live cynaobacteria, we can only hypothesize what happens during the process of clump formation. If the trichomes react to grazer attacks by backing away from the spot where they were attacked (Fiałkowska \& Pajdak-Stós 1997), most probably all attacked trichomes moved towards the center of the clump. According to Hoiczyk (2000),
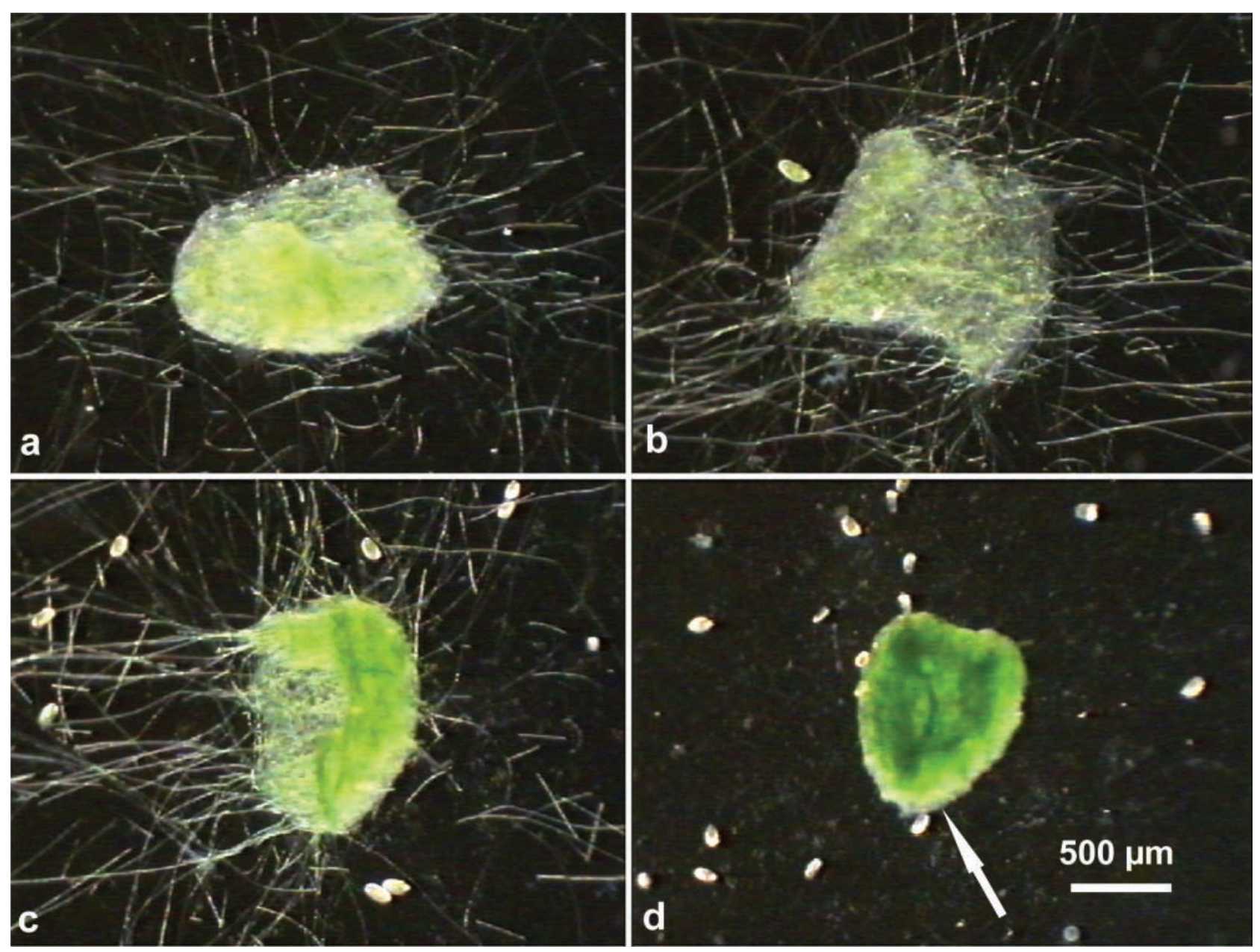

Fig. 7. Appearance of cyanobacteria Phormidium sp. mats 3 d after ciliate Furgasonia blochmanni release: (a) control, (b) 10 ciliates $\mathrm{ml}^{-1}$, (c) 100 ciliates $\mathrm{ml}^{-1}$ and (d) 600 ciliates $\mathrm{ml}^{-1}$. The arrow shows a thin layer of mucilage embedding the initial piece of mat. Note the density of trichomes inside the Phormidium sp. clump (d) 
gliding movements are always accompanied by slime secretion, whereas when filaments are immobilized by a micromanipulator, the slime is actively translocated over the filament's surface. The types of movements involved in clump formation observed in our experiment were similar to those described by Hoiczyk (2000). It seems likely that the mucilage shielding the clump is accumulated during rotating movements as well as trichome withdrawal.

Clump formation in response to high grazer pressure is an excellent means of defense. Its effectiveness is clearly reflected in the ciliates' condition. During the first $24 \mathrm{~h}$ there was a dramatic decrease in the percentage of satiated ciliates, and it remained very low until the end of the experiment in spite of the apparent surplus of food in the experimental wells (Fig. 4). Concomitantly the fraction of cysts increased, especially at the end of the experiment (Fig. 5). Ciliates are known to respond to starvation by encystment (Fenchel 1987). Most probably the high percentage of encysted ciliates was the result of food deprivation, as trichomes staying inside clumps are completely inaccessible to the grazers. One can argue that in this case ciliate starvation simply was the consequence of strong food competition caused by a high initial grazer density. However, apart from the first day, ciliates could not reach the maximum rate of multiplication because after $24 \mathrm{~h}$ most of them were starved (Fig. 4). Increasing encystment (Fig. 5) also indicates that the number of ciliates probably was not high enough to obstruct food intake to the extent that could be predicted on the basis of the number of starving grazers. On the other hand, the number of trichomes leaving the initial piece of mat when not disturbed by ciliates (Fig. 1a) was so high that if cyanobacterium would be deprived of any kind of defense, it should easily provide food for such an amount of ciliates. Fig. 7d shows how densely the trichomes were packed inside a clump. When attending our cultures we frequently observed that tearing such a clump with a pippette always made cyanobacteria accessible for ciliates, which started feeding immediately. Though the influence of food competition cannot be excluded, it seems that cyanobacteria defense is the major factor causing ciliate starvation.

Oliver \& Ganf (2000) showed that filamentous cyanobacteria could not withstand grazing pressure over a certain level, whereas large inedible colonies could. Apparently, clump formation serves the same purpose-it ensures survival even under such pressure that solitary trichomes most likely could not withstand.

The issue of a possible role of mucilage in cyanobacteria resistance to ciliate grazer has also been raised by Canter et al. (1990). They observed that all the cyanobacteria that survived the period of intense Nassula sp. grazing in Esthwaite Water had wide mucilage envelopes. Those observations seemed to support their view that the presence of mucilage may play an important role in cyanobacteria susceptibility to grazing. Canter et al. (1990) also stated that it was not known whether Nassula sp. can get hold of filaments embedded in mucilage. At the same time they point out that short filament ends sticking out of the mucilage probably provide the ciliate with access to its food. Those assumptions are in accordance with our observations. Ciliates can ingest trichomes projecting from the mucilage layer (Fig. 3), but, as we showed in the paper on Phormidium autumnale (Pajdak-Stós et al. 2001), a ciliate cannot cut off a trichome deeper than at the edge of mucilage, and the remaining part of the latter retreats within the EPS layer. However, some ciliates possess the ability to suck the trichome out of the sheath (Fiałkowska \& Pajdak-Stós 1997), so most probably if a trichome had been short enough it could have been sucked out of the mucilage. In any case the first step for a ciliate is to get hold of the trichome, which is impossible when trichomes are embedded in the mucilage.

The trichomes inside such a clump do not remain completely motionless. Sporadically, some of them glide out of the mat, where they most probably are immediately attacked by ciliates, which on the one hand would account for very few fed ciliates at the end of experiment, and on the other, for the lack of trichomes projecting from the clump.

In the treatment with medium grazer density (100 ciliates $\left.\mathrm{ml}^{-1}\right)$, Phormidium sp. did not form clumps; this, however, does not mean that they were completely defenseless. Cyanobacteria can defend themselves by means of the stiff, empty sheath protruding from the end of a trichome (Fiałkowska \& Pajdak-Stós 1997). In the current experiment, the percentage of trichomes ending with an empty sheath increased only slightly during the first $24 \mathrm{~h}$, but during the next $48 \mathrm{~h}$ the increase sharply accelerated (Fig. 6). Consequently, the fraction of satiated ciliates decreased noticeably on the third day of the experiment. The mode of defense adopted in this case was almost as effective as that described above but was somehow delayed. It seems to take more time to produce sheaths strong enough to be of use in defense than to assume the shape of clumps. A defense based on sheath production would be too slow to protect trichomes gliding separately on the bottom from very frequent grazer attacks. When grazer density is not extremely high and their attacks are not so frequent, trichomes have enough time to produce sheaths. Hoiczyk (1998) describes a sheath as a tube visible by phase contrast or differential inter- 
ference contrast, which appears only in old cultures. Our experiment, using the strain of Phormidium described as $\mathrm{Ph} 2$ in a previous paper (Fiałkowska \& Pajdak-Stós 1997), seems to confirm that under strong grazer pressure cyanobacteria are able to accelerate production of sheath-building materials.

The density of 10 ciliates $\mathrm{ml}^{-1}$ is too low to induce any kind of defense. The pattern of trichome migration was similar to that in the control, and the ciliates remained satiated throughout the experiment, thanks to unlimited access to food (Fig. 4). In such a case the ciliates keep dividing. After some time the grazer density may be high enough to trigger cyanobacteria defense, but this should depend on the multiplication rate of both organisms.

Our results show that cyanobacteria are able to adopt different modes of defense in response to different degrees of grazer pressure. In all probability, this is the reason why ciliates, however capable of limiting the amount of cyanobacteria and their colonization, cannot eliminate them completely from the habitat. The phenomenon described here may help in understanding the occurrences observed in natural habitats. Canter et al. (1990) noticed that blooms of planktonic cyanobacteria are accompanied by an increasing number of Nassula sp. grazers. Their intense grazing resulted in a dramatic decline of some cyanobacteria species, but their number was never reduced below a certain level. What is more, after decline and encystment of Nassula sp., the population of the cyanobacteria quickly recovered (Canter et al. 1990). It cannot be excluded that the described cyanobacteria also developed some kind of defense.

Gliding motility is known to help cyanobacteria to optimize their position in the habitat (Haeder \& Hoiczyk 1992). Remaining inside dense clumps or stiff sheaths apparently has advantages as a protection against grazers, but at the same time it limits the cyanobacteria's ability to search actively for the most suitable habitat. It can be expected that when the grazer pressure lessens due to their encystment, trichomes start to move out of the initial mat, providing food for the remaining grazers, as has already been described (Pajdak-Stós et al. 2001). Even the few grazers with easy access to food would quickly restore the population.

The described phenomenon of adopting different modes of defense depending on grazer pressure shows the plasticity of organisms seemingly as simple as cyanobacteria. It is still to be determined whether the phenomenon is a common feature of cyanobacteria. To determine how the cyanobacteria's ability to adopt different modes of defense influences their chances of survival and dispersion in natural habitats requires further studies.
Acknowledgements. We thank J. Kozłowski, W. Fiałkowski and M. Czarnołski for many valuable comments on an earlier version of this paper, and M. Jacobs for help in editing it. The manuscript also benefited greatly from the comments of referees. This work was supported with grant KBN 6 PO4F 10721.

\section{LITERATURE CITED}

Broenmark C, Miner J (1992) Predator-induced phenotypical change in body morphology in crucian carp. Science 258:1348-1350

Canter HM, Heaney SI, Lund JWG (1990) The ecological significance of grazing on planktonic populations of cyanobacteria by the ciliate Nassula. New Phytol 114:247-263

Dodson S (1989) Predator-induced reaction norms. Cyclic changes in shape and size can be protective. Bioscience 39:447-452

Eisler K, Bardele CF (1986) Cortical morphology and morphogenesis of the nassulid ciliates Furgasonia blochmanni Faure-Fremiet, 1967 and Nassula citrea Kahl, 1930. Protistologia T. XXII, fasc 4:461-476

Fenchel T (1987) Ecological physiology: other aspects. In: Fenchel T (ed) Ecology of protozoa. Science Tech, Madison, p 63-75

Fiałkowska E, Pajdak-Stós A (1997) Inducible defense against a ciliate grazer, $P$. dubius dubius, in two strains of Phormidium (cyanobacteria). Proc R Soc Lond B 264:937-941

Fyda J (1998) Predator-induced morphological changes in the ciliate Colpidium (Protozoa, Ciliophora). Eur J Protistol 34: 111-117

Fyda J, Wiąckowski K (1998) Benefits and costs of predatorinduced morphological changes in the ciliate Colpidium kleini (Protozoa, Ciliophora). Eur J Protistol 34:118-123

Haeder DP, Hoiczyk E (1992) Gliding motility. In: Melkonian $M$ (ed) Algal cell motility. Chapman \& Hall, London, p 1-38

Harvell CD (1990) The ecology and evolution of inducible defenses. Q Rev Biol 65:323-340

Havel JE (1987) Predator-induced defenses: a review. In: Kerfoot WC, Sih A (eds) Predation. Direct and indirect impact on aquatic communities. University Press of New England, Hanover, p 263-278

Hoiczyk E (1998) Structural and biochemical analysis of the sheath of Phormidium uncinatum. J Bacteriol 15: 3923-3932

Hoiczyk E (2000) Gliding motility in cyanobacteria: observations and possible explanations. Arch Microbiol 174:11-17

Kuhlman HW, Heckmann K (1985) Interspecific morphogenes regulating prey-predator relationships in protozoa. Science 227:1347-1349

Lewis SM, Norris JN, Searles RB (1987) The regulation of morphological plasticity in tropical reef algae by herbivory. Ecology 68:636-641

Luerling M (1999) Grazer-induced colony formation in Scenedesmus: costs of being colonial? In: Luerling $M$ (ed) The smell of water. Grazer-induced colony formation in Scenedesmus. Wageninen Agricultural University, p 127-140

Luerling M, Van Donk E (1997) Morphological changes in Scenedesmus induced by infochemicals released in situ from zooplankton grazers. Limnol Oceanogr 42:783-788

Oliver RL, Ganf GG (2000) Freshwater blooms. In: Whitton BA, Potts M (eds) The ecology of cyanobacteria. Kluwer Academic Publishers, Dordrecht, p 149-194

Pajdak-Stós A, Fiałkowska E, Fyda J (2001) Phormidium 
autumnale (Cyanobacteria) defense against three ciliate grazer species. Aquat Microb Ecol 23:237-244

Smith DC, Van Buskirk J (1995) Phenotypic design, plasticity, and ecological performance in two tadpole species. Am Nat 145:211-233

Sokal RR, Rohlf FJ (1981) Biometry, 2nd edn. WH Freeman, New York

Stanier RY, Kunisawa M, Mandel M, Cohen-Bazire G (1971) Purification and properties of unicellular blue-green algae (order Chroococcales). Bacteriol Rev 35:171-205

Tollrian R, Harvell CD (1999) The evolution of inducible defense: current ideas. In: Tollrian R, Harvel CD (eds) The ecology and evolution of inducible defenses. Princeton University Press, Princeton, p 306-323

Tuffrau M (1967) Perfectionnements et pratique de la technique d'imprégnation au protargol des infusoires ciliés. Protistologica 3:91-98

Van Alstyne KL (1988) Herbivore grazing increases poly-

Editorial responsibility: David Caron,

Los Angeles, California, USA phenolic defenses in the intertidal brown alga Fucus distichus. Ecology 69:655-663

Vigues B, Blanchard MP, Bouchard P (1999) Centrin-like filaments in the cytopharyngeal apparatus of the ciliates Nassula and Furgasonia: evidence for a relationship with microtubular structures. Cell Motil Cytoskeleton 43:72-81

Washburn JO, Gross ME, Mercer DR, Anderson JR (1988) Predator-induced trophic shift of a free-living ciliate: parasitism of mosquito larvae by their prey. Science 240: 1193-1195

Wiąckowski K, Starońska A (1999) The effect of predator and prey density on the induced defense of a ciliate. Funct Ecol 13:59-65

Wilbert N (1975) Eine verbesserte Technik der Protargolimpraegnation für Ciliaten. Mikrokosmos 6:171-182

Wolfe GV, Steinke M, Kirst GO (1997) Grazing-activated chemical defense in a unicellular marine alga. Nature 387:894-897

Submitted: April 18, 2001; Accepted: November 8, 2001 Proofs received from author(s): February 15, 2002 